\title{
DISCURSOS SOBRE A(S) LINGUA(S) E IDEOLOXÍAS LINGÜÍSTICAS NOS MEDIOS DE COMUNICACIÓN*
}

\author{
José del Valle \\ The Graduate Center - The City University \\ of New York
}

\footnotetext{
* Algunhas seccións deste artigo foron xa publicadas en: «Política del lenguaje y geopolítica: España, y la población latina de Estados Unidos», en Silvia Senz e Montse Alberte (eds.), El dardo en : Melusina, $2011 \mathrm{e}$ «Las representaciones ideológicas del lenguaje: discurso glotopolítico y panhispanismo», en José del Valle y Elvira Narvaja de Arnoux (eds.), Special Issue of Spanish in Context, 7(1): 1-24, 2010, escrito en colaboración con Elvira Narvaja de Arnoux.
} 

O estudo da dimensión social da linguaxe e da compoñente lingüística da sociedade ten unha historia longa e ben coñecida, durante a cal se foi tecendo unha rede complexa de investigacións e saberes. Nela están representados intereses distintos en relación coa linguaxe e a sociedade, e aproximacións alternativas a eles, que deron lugar á cristalización de disciplinas complementarias tales como a sociolingüística (e.g. Fasold 1990), a socioloxía da linguaxe (e.g. Fasold 1987), a antropoloxía lingüística (e.g. Duranti 2001) e a glotopolítica (e.g. Arnoux 2008a, Del Valle 2007, Guespin e Marcellesi 1986). Á marxe de que o interese destes campos de estudo se poida orientar máis cara ao sistema lingüístico ou cara á súa orixe e función social, e á marxe de que a aproximación ao obxecto se poida facer desde posicións máis indutivas ou dedutivas, o feito é que as devanditas disciplinas coinciden ao adoptaren unha visión fundamentalmente contextual da linguaxe: o fenómeno lingüístico constitúese como tal nun contexto que, segundo os intereses e a aproximación do observador, pode ser definido en termos preferentemente sociais, culturais ou políticos.

Desde esta perspectiva, a linguaxe preséntase, por unha parte, como unha práctica social que reflicte, á vez que talla, os contornos das colectividades humanas e, por outra, como un fenómeno esencialmente variábel. E, ao referírmonos a esta característica pensamos, por suposto, no nivel micro, onde se manifestan por exemplo variábeis fonolóxicas, pero tamén no nivel macro, onde falar significa, máis alá do uso dunha variante fronte a outra, a primacía ou non do uso dunha lingua sobre outra nun contexto determinado. A variación - tal como revelaron a sociolingüística, a pragmática e a etnografía da comunicación- é sistemática, e a súa sistematicidade maniféstase non só no poder preditivo de determinados factores do contorno lingüístico senón, sobre todo, na relación co contexto.

Ante este horizonte, a linguaxe figúrase como o uso dun repertorio complexo e plurilectal (Zentella 1997: 41-55), en actos onde son negociadas as identi- 
dades sociais, e onde se poñen en xogo os recursos comunicativos dos interlocutores (Le Page e Tabouret-Keller 1985). En consecuencia, a descrición e análise do perfil lingüístico dun grupo ou grupos, recortados do universo social polo investigador, debe atender tanto ao repertorio de lectos e xéneros discursivos que son realizados como aos réximes de normatividade que, dentro desa colectividade concreta, articulan a relación entre as formas lingüísticas e o seu valor social.

Partamos do feito de que toda colectividade humana está socialmente estruturada, e de que se caracteriza pola existencia de determinadas relacións de poder. Estes factores contextuais son precisamente aqueles que estruturan os réximes de normatividade nos cales se inscribe a praxe lingüística, é dicir, o mercado lingüístico que asigna valores diferentes aos usos da linguaxe. O lugar que un individuo ocupe na sociedade, os espazos a que teña acceso e a capacidade que posúa para negociar o seu rol nese contorno determinarán a súa predisposición a actuar dun xeito particular. E non só iso, senón que condicionarán tamén as valoracións que fixer das accións doutros $-\mathrm{o}$ individuo desenvolve, en terminoloxía de Bourdieu, un habitus. Estará, por tanto, en disposición de usar unha ou varias linguas, unha ou outra lingua, unha ou outra variedade dunha lingua, dependendo da súa localización e capacidade de manobra dentro do complexo tecido social. E desta mesma posición —e, por tanto, do seu grao de sometemento ou autonomía a respecto do réxime de normatividade imperante- dependerá a súa disposición para valorar dunha maneira ou doutra o espectro de prácticas lingüísticas que achar. A operación máis obvia de intervención no mercado lingüístico, de construción dun réxime de normatividade altamente coercitivo, é a intervención do Estado na estandarización lingüística e a imposición do estándar en diversos ámbitos da vida social (Haugen 1972, Joseph 1987, Milroy e Milroy 1999):

La lengua oficial se ha constituido vinculada al Estado. Y esto tanto en su génesis como en sus usos sociales. Es en el proceso de constitución del Estado cuando se crean las condiciones de la creación de un mercado lingüístico unificado y dominado por la lengua oficial: obligatoria en las ocasiones oficiales (escuela, administraciones públicas, instituciones políticas, etc.), esta lengua de Estado se convierte en la norma teórica con que se miden objetivamente todas las prácticas lingüísticas (Bourdieu 1999: 19). 
O valor da lingua oficial deriva, en efecto, do poder do Estado para recompensar aqueles que a coñecen, e para sancionar aqueles que a ignoran. Mais o seu valor simbólico - a naturalización da súa superioridade e, por tanto, o establecemento da súa condición hexemónica (Gramsci 1991, Williams 1977)—é fundado en múltiples discursos — moitos deles lingüisticamente banais- que xeran o universo de asociacións que lexitiman a autoridade da lingua oficial á marxe do poder coercitivo do Estado. Non só na imposición xurídica da lingua e nas gramáticas prescritivas se acha a chave do xogo de poderes inscrito nun determinado réxime de normatividade.

Por tanto, para o estudo do desenvolvemento e funcionamento dos réximes de normatividade é imprescindíbel identificarmos como obxecto de análise as representacións sociolingüisticas, é dicir, aquelas que, por un lado, se refiren a obxectos lingüísticos (linguas, variedades, falas, acentos, rexistros, xéneros, modos de ler ou de escribir, etc.) e que, por outro, implican avaliacións sociais deses obxectos e dos suxeitos con que son asociados (Bourdieu 1999). As representacións sociolingüísticas, como adiantaba hai uns minutos, actúan na estruturación do contexto. Bourdieu sinala que inciden nas identidades sociais na medida en que instauran clasificacións que tornan visíbeis os grupos para si e para os outros. Henri Boyer (2003) asociounas a outras nocións que operan dentro das diversas disciplinas que estudan a «interficie» onde coexisten a linguaxe e a sociedade: as actitudes, os estereotipos, a imaxe e a opinión.

Son múltiples, en efecto, non só as formas que adoptan senón tamén as zonas discursivas onde se manifestan as representacións sociolingüísticas: encontrámolas nos textos que regulan política e xuridicamente o uso da linguaxe (programas políticos, leis e regulamentos), nos textos que definen os obxectos lingüísticos (gramáticas, dicionarios, libros de estilo), nos textos que os tematizan (artigos de opinión sobre, por exemplo, o uso correcto), nas imaxes mediáticas que asocian determinados colectivos con determinadas formas de fala (cómicos que nas súas imitacións reproducen e crean estereotipos sociolingüísticos) e na propia praxe lingüística entendida, como diciamos arriba, como acción na cal os interlocutores negocian as súas identidades sociais.

Na última década do século XX, o estudo das representacións da linguaxe foi enriquecido polo desenvolvemento dunha nova categoría teórica: as ideoloxías lingüisticas. Xa Louis Althusser, na súa clásica definición, ligara conceptualmen- 
te representación e ideoloxía: «la ideología es un sistema [...] de representaciones (imágenes, mitos, ideas o conceptos, según los casos) dotadas de una existencia y de un papel históricos en el seno de una sociedad dada» (1968: 191-192). A adopción da etiqueta «ideoloxía» implica, evidentemente, perigos que non deben ser desbotados. É frecuente, por exemplo, que se defina como conciencia falsa ou até como distorsión interesada da realidade. É tamén xeral o seu uso como doutrina adoptada por unha institución ou movemento social e vinculada a plans concretos de acción política. Non son estes os sentidos en que o termo foi produtivo nos estudos da linguaxe que aquí referimos (Eagleton 1991). Nesta tradición, «ideoloxía» remite tanto ao ámbito das ideas, das crenzas, das representacións subxectivas, como ao ámbito das prácticas, aos procesos que constitúen o significado social da actividade humana. Aparecen en todo caso - xa sexan representacións ou prácticas - socialmente localizadas e deben ser descritas e interpretadas no contexto das múltiples negociacións que producen, reproducen ou disputan a orde social (Woolard 1998: 5-9).

Como dicía, desde diferentes ámbitos xeoacadémicos e espazos disciplinarios, foise desenvolvendo nos últimos anos un tipo de reflexión que aspira a identificar a continxencia histórica, a localización social e a función política de «imaxes, mitos, ideas ou conceptos» lingüísticos — volvemos así aos termos escollidos por Althusser. Desde un sector da antropoloxía lingüística — nun ámbito fundamentalmente estadounidense- (Schieffelin et al. 1998, Kroskrity 2000) foi acuñado o sintagma language ideologies para designar «representations, whether explicit or implicit, that construe the intersection of language and human beings in a social world [...] mediating link[s] between social forms and forms of talk» (Woolard 1998: 3). A adopción dun termo novo indicaba, en primeiro lugar, a vontade de problematizar a pegada naturalizadora que a mirada tradicional da antropoloxía deixara no ámbito cultural: «Ironically, anthropology too often has participated in a kind of naturalization of the cultural, casting culture as a shared and timeless prime motivator. The emphasis of ideological analysis on the social and experiential origins of systems of signification helps counter such naturalization» (Woolard 1998: 10).

En segundo lugar, a adopción deste novo sintagma sinalaba que o interese antropolóxico pola linguaxe —ou o interese deste grupo de antropólogos, polo menos - se orientaría agora cara ao estudo das raíces e ramificacións sociais das 
súas representacións: "[T]his [political-economic] emphasis was hardly unexpected, given the acknowledged importance in much language ideological research of understanding the language beliefs and practices of social groups as strongly connected to group interests within society» (Kroskrity 2000: 2).

O libro editado por Schieffelin, Woolard e Kroskrity, aparecido en 1998, tiña a súa orixe nun simposio organizado en 1991. Pola mesma época (tan só un ano antes) publicábase Ideologies of language, proxecto editado por John E. Joseph e Talbot J. Taylor. Estaba escrito tamén en inglés e aparecía claramente situado en ámbitos universitarios e editoriais anglosaxóns (publicado pola editorial Routledge); pero a súa localización xeoacadémica era un pouco distinta á dos antropólogos citados. Dunha parte, procedían da lingüística e, da outra, a súa adscrición profesional exhibía un perfil algo máis variado: dos doce colaboradores, só catro deles escribían desde universidades estadounidenses, e catro escribían desde institucións non anglosaxoas (Bélxica e Hong Kong). Con todo, non convén esaxerar as diferenzas. Aínda que non procedían, como dixemos, da antropoloxía senón da lingüística, Joseph e Taylor declaraban de entrada o seu "protestantismo» fronte esta: «we are all linguistic "protestants", even if belonging to distinct denominations» (1990: 2). E aínda que dedicaban o volume á análise de modelos de representación das linguas e da linguaxe desenvolvidos por lingüistas — situándose así, dalgún xeito, en diálogo coa historiografía lingüística (Koerner 1995) e coa historia das ideas lingüísticas (Auroux 1989)—, facíano desde unha visión non só contextual e histórica do coñecemento, senón tamén construtivista. A coincidencia entre ambos os programas, de feito, non consiste unicamente no recurso á etiqueta ideolóxica senón que emerxe da adopción dunha teoría da linguaxe que visibiliza as amputacións sufridas por este obxecto a mans da lingüística autónoma; a cal, para illar a gramática e facela dese modo susceptíbel dun determinado tipo de descrición científica, procedera a separar ese obxecto do contexto de uso, a privilexiar a súa función referencial e a descartar o valor empírico da conciencia lingüística dos falantes (Kroskrity 2000: 4-5). A naturalización e universalización das concepcións máis formais da linguaxe, segundo Bourdieu, «escamotea la cuestión de las condiciones económicas y sociales de la adquisición de la competencia legítima y de la constitución del mercado donde se establece e impone esta definición de lo legítimo y de lo ilegítimo» (1999: 18). A coincidencia entre os dous grupos de investigadores ao avanzaren unha nova categoría teórica, ideoloxías lingüísticas, é produto precisamente dun desexo comparti- 
do por rescataren da marxinación elementos que son considerados centrais para comprender o funcionamento da linguaxe — «the concept of language ideology is the offspring of two neglected forces: the linguistic "awareness" of speakers and the (nonreferential) functions of language» (Kroskrity 2000: 5) — e do recoñecemento de que a súa representación — producida xa for dentro ou fóra das fronteiras disciplinarias da lingüística - emerxe nun contexto concreto e actúa sobre ese mesmo contexto. Dito doutra maneira, e retomando así o fío conceptual iniciado arriba, as ideoloxías lingüísticas son propostas como elementos fundamentais para a identificación e análise dos réximes de normatividade nos cales son interpretadas necesariamente as prácticas lingüísticas.

Nunha tentativa por recoller nunha definición operativa as diversas dimensións sinaladas nas ideoloxías lingüísticas, Del Valle defíneas como «sistemas de ideas que articulan nociones del lenguaje, las lenguas, el habla y/o la comunicación con formaciones culturales, políticas y/o sociales específicas. Aunque pertenecen al ámbito de las ideas y se pueden concebir como marcos cognitivos que ligan coherentemente el lenguaje con un orden extralingüístico, naturalizándolo y normalizándolo, también hay que señalar que se producen y reproducen en el ámbito material de las prácticas lingüísticas y metalingüísticas, de entre las cuales presentan para nosotros interés especial las que exhiben un alto grado de institucionalización» (2007: 20).

Como sinala o último punto da definición proposta, as ideoloxías lingüísticas inscríbense en réximes de normatividade que, ao actuaren desde as institucións, son xeradores de discursividades lexítimas. Estes dispositivos poden ser inferidos das propias prácticas discursivas ou das avaliacións que os falantes fan das formas nun determinado espazo social; pero tamén se poden expresar en textos reguladores como gramáticas, dicionarios, manuais de estilo ou disposicións editoriais destinadas aos autores de artigos científicos. Bourdieu (1988) sinala ao respecto que as clases dominantes, na imposición dunha orde simbólica, realizan unha tarefa codificadora que implica tamén a imposición de esquemas de percepción e de avaliación das formas lingüísticas e de dispositivos normativos tendentes a orientaren prácticas e crenzas. Se pensarmos no proceso de conformación dos Estados nacionais, un dispositivo normativo altamente institucionalizado e eficaz na consolidación lingüística da comunidade é constituído polos medios de comunicación. A prensa escrita, fundamentalísima até finais do sécu- 
lo XX, alén de operar como un dos soportes da comunidade imaxinada moderna por antonomasia - a nación-, constituíuse tamén en plataforma de proxección das maneiras de falar socialmente admitidas. Por unha parte, articulou, a través do exemplo ofrecido pola súa propia prosa, o universo ideolóxico que definía o correcto e aceptábel e, por outra, articulou un espazo discursivo onde a linguaxe se constituía en obxecto de disputas cuxa relevancia, como revela a análise, transcendía o aspecto puramente lingüístico.

Precisamente foi a prensa escrita o medio escollido por Domingo Faustino Sarmiento, Andrés Bello, Rafael Minvielle e demais para polemizaren sobre a natureza da lingua castelá a mediados do século XIX, sobre o seu destino en América, sobre a organización dun dispositivo institucional de xestión do idioma, sobre a relación entre este e o pobo, sobre o papel de España no desenvolvemento das novas nacións. Foi nas páxinas de El Mercurio de Valparaíso, El Mercurio de Santiago, El Progreso, La Gaceta del Comercio... onde se librou unha batalla lingüístico-ideolóxica que habería de incidir decisivamente sobre a conciencia lingüística nacional, latinoamericana e panhispánica.

Foi en revistas tales como La Ilustración Ibérica, La Ilustración Española y Americana ou La Revista Española de Ambos Mundos onde se realizaron as formulacións orixinarias do panhispanismo, que ancoraban a unidade esencial entre España e as súas antigas colonias nunha cultura idéntica garantida polo idioma identificado como «común». Nesas publicacións foi onde o discurso da conquista se converteu en eixe articulador da «gran familia española» e a orixe, relixión, costumes e lingua compartidos como elementos constitutivos do ethos panhispánico.

Será tamén a prensa escrita o medio escollido por Juan Valera para reprochar ao filólogo colombiano Rufino José Cuervo a súa apocalíptica predición ao respecto da inevitábel ruptura do castelán. Desde as páxinas de Los Lunes del Imparcial de Madrid, de La Nación de Bos Aires, da Tribuna de México, afirmou máis dunha vez a condición panhispánica do idioma e a capacidade da intelectualidade, de aquí e de alá, para defender a integridade do idioma que unía inexorabelmente os españois de ambos lados do Atlántico, como daquela se dicía.

Os medios de comunicación, cuxas plataformas de expresión foron ampliadas nos nosos días como consecuencia de desenvolvementos tecnolóxicos ben coñecidos, continuaron a ter un papel central —inclusive máis central que no 
pasado — na articulación de políticas lingüísticas orientadas ao control do valor simbólico do idioma.

Ao chegarmos a este punto, convén aclarar que ao falar de política e planificación lingüística non me refiro só a unha disciplina práctica, a unha sorte de enxeñaría social coas súas ramas teóricas e aplicadas. Non me refiro á fase inicial desta disciplina académica que Thomas Ricento ten caracterizado pola súa dependencia epistemolóxica do estruturalismo e do positivismo, pola súa orientación pragmática (actividade dirixida á solución de problemas lingüísticos) e por responder ás condicións dun contexto histórico concreto, a saber, os procesos poscoloniais de construción nacional e as teorías do desenvolvemento (Ricento 2000: 197-200).

Einar Haugen, un dos pais fundadores do campo, ofrecía a seguinte definición - máis apropiada en realidade, desde a nosa perspectiva actual, para describir unha das actividades que, sen ser en absoluto a única, constitúe o obxecto da PPL, a estandarización:

Por planificación lingüística entiendo la actividad de preparar una ortografía, gramática y diccionario normativos para guía de escritores y hablantes en una comunidad de habla no homogénea. En esta aplicación práctica del conocimiento lingüístico vamos más allá de la lingüística descriptiva para adentrarnos en un área donde el juicio de valor se manifiesta en la toma de decisiones sobre formas lingüísticas alternativas disponibles (Haugen 1959: 8, cit. en Hornberger 2006: 26).

Na súa lucidez, Haugen apuntaba xa cara ao carácter político da estandarización e sinalaba a posición histórica do suxeito que se envolve na actividade da planificación. Esta condición histórica do proceso deu lugar, evidentemente, a que co paso do tempo xurdisen contribucións ao campo desde aquilo que Ricento (2000: 200-203) chama a sociolingüística crítica, achegas onde a estandarización é concibida non só como a solución técnica a un problema práctico senón como un proceso fundamentalmente ideolóxico.

Na primeira fase do desenvolvemento do campo, por tanto, a estandarización era concibida en termos prácticos: un saber técnico ao servizo do desenvolvemento nacional. Conceptualizábase como un proceso de xestión dun recurso que se realizaba por medio de varios subprocesos: nun primeiro nivel encontrábanse a 
planificación do corpus e a planificación do status. A primeira, pola súa vez, estaría formada pola codificación - establecemento dun sistema de escritura, unha gramática e un léxico- e a elaboración — creación de mecanismos que manteñan a lingua sempre a punto, sempre ao día, velando, por exemplo, pola súa modernización léxica. A segunda, a planificación do status, constaría pola súa parte de dous proxectos: a selección da variedade, variedades ou elementos que deben servir como base para a norma e a súa implementación, é dicir, o deseño e posta en práctica de medidas que levaren ao seu uso xeneralizado nos contextos desexados. Kaplan e Baldauf ofrecen a seguinte definición deste proceso: «La implementación de un plan lingüístico se centra en la adopción y difusión de una variedad lingüística que ya ha sido seleccionada y codificada. Esto se hace con frecuencia a través del sistema educativo y de otras leyes y normativas legales que incentivan y/o exigen el uso del estándar y quizás desincentivan el uso de otras lenguas o dialectos» (1997: 36).

Como se tira desta definición, a implementación consiste na proxección do plan lingüístico en cuestión sobre a comunidade afectada, é dicir, inclúe as múltiples estratexias que os axentes da política lingüística deben deseñar para persuadiren a poboación da bondade e conveniencia do plan. Unha vez seleccionada a lingua ou dialecto (ou linguas e dialectos) que han de servir como base para o desenvolvemento da norma, completada a codificación e dispostos os mecanismos de elaboración, é imprescindíbel conseguir que os falantes acepten a visión da comunidade lingüística que lles é proposta, e evidentemente a lexitimidade das institucións ás cales se encomenda a formulación da política lingüística. Estariamos aquí ante un proceso que poderiamos chamar de planificación do status simbólico da lingua. Certo é que, como indican Kaplan e Baldauf, o sistema educativo acostuma ter un papel central como instrumento ao servizo da implementación. Ora ben, non hai que esquecer a relevancia doutros campos discursivos - como por exemplo, e de maneira moi especial, os medios de comunicación - na difusión de ideas e prácticas que, despois de enraizadas na opinión pública e convertidas en sentido común, faciliten a realización de proxectos políticos e lexitimen arranxos socioeconómicos concretos.

Este é precisamente o panorama que nos ofrecen as políticas de promoción do español dos últimos vinte anos. Refírome concretamente ás chamadas políticas lingüísticas panhispánicas, un conxunto de accións institucionais que 
teñen como obxecto explícito o idioma e que se articulan desde a Real Academia Española (RAE) a través da Asociación de Academias de la Lengua Española (ASALE). Como veremos, fan parte dunha complexa coreografía de intervencións nos campos lingüístico e cultural por parte de axencias gobernamentais, empresas e fundacións, e no seu deseño e implementación o obxectivo prioritario é a construción dunha imaxe institucional. Os medios de comunicación foron unha ferramenta fundamental ao servizo da súa proxección.

O propio cualificativo adoptado para identificar estas políticas demostra que a preocupación central da RAE nestes anos foi a súa relación coa América hispanofalante. Esta relación foi traballada principalmente a través de dúas estratexias: o fortalecemento da ASALE e a adopción de iniciativas lexicográficas, gramaticais e ortográficas ancoradas nunha normatividade policéntrica. Aqueles que seguen de preto a actividade da RAE saben ben que o vello lema «limpia, fija y da esplendor», tan explícito canto á clásica función profiláctica da institución, foi progresivamente desprazado cara a unha zona menos visíbel da imaxe pública que a Academia ten proxectado de si mesma. Na súa páxina web, nunha brevísima sección de introdución histórica, a RAE describe a súa propia evolución nos seguintes termos: «La institución ha ido adaptando sus funciones a los tiempos que le ha tocado vivir. Actualmente, y según lo establecido por el artículo primero de sus Estatutos, la Academia "tiene como misión principal velar porque los cambios que experimente la Lengua Española en su constante adaptación a las necesidades de sus hablantes no quiebren la esencial unidad que mantiene en todo el ámbito hispánico”» (www.rae.es). A nova imaxe pública da RAE preséntase de maneira inequívoca nun texto chave para a comprensión do proxecto actual, La nueva política lingüistica panhispánica, publicado en 2004 pola RAE e asinado pola ASALE: «En nuestros días, las Academias, en una orientación más adecuada y también más realista, se han fijado como tarea común la de garantizar el mantenimiento de la unidad básica del idioma, que es, en definitiva, lo que permite hablar de la comunidad hispanohablante, haciendo compatible la unidad del idioma con el reconocimiento de sus variedades internas» (ASALE 2004: 3). Neste fragmento, vemos condensadas as ideas que definen a estratexia para a defensa do idioma e que nos permiten entender a súa función no contexto máis amplo dos intereses económicos e xeopolíticos de España: primeiro, a xa mencionada adopción dun modelo de normatividade policéntrica 
que sexa asumíbel polas academias americanas (e polas sociedades da América hispanofalante) e, segundo, a instrumentalización do español, da súa unidade (máis conceptual que formal), como cemento da comunidade panhispánica, é dicir, a proxección dunha imaxe do idioma que convenza a opinión pública da existencia desta comunidade e da lexitimidade dos seus custodios. Cómpre sinalar que a ansia por preservar a unidade formal da lingua, é dicir, por reducir a variación dialectal para evitar a fragmentación e protexer a unidade (actitude tradicionalmente identificada como purismo), é marxinal nos discursos actuais que xorden do contorno académico. É máis, o abrazo da variedade, como acabamos de indicar, pasou a ser un dos eixes da política lingüística panhispánica en tanto que aquilo que interesa agora é protexer a unidade conceptual do idioma, é dicir, procurar que o español, por riba da súa diversidade interna, sexa concibido como unha soa lingua que representa e posibilita a existencia dunha comunidade cultural e, sobre todo, dun mercado. A transcendencia desta nova aproximación ao idioma foi sinalada inequivocamente polo actual director, Víctor García de la Concha: «creemos que con ello estamos prestando un servicio cuyo interés rebasa lo estrictamente lingüístico para situarse en un valor importantísimo en la integración de Comunidad Iberoamericana de Naciones, y creemos que esto se realiza como el mejor servicio al robustecimiento de la unidad del español, pero con el respeto más absoluto a las realizaciones variadas que ese español unido tiene en cada una de las regiones» ${ }^{1}$.

Xa vimos que a vocación panhispánica de España non é nova, e remóntase ao período en que, despois da consolidación da independencia da maioría das colonias americanas, se comezou a pensar unha política exterior que priorizase a construción dunha relación privilexiada coa América hispanofalante e paralelamente a articular un discurso de unidade cultural panhispánica ancorada no idioma. O panhispanismo, ao longo do seu desenvolvemento histórico, tivo que se enfrontar a numerosos obstáculos que, como apuntei brevemente hai uns minutos, se manifestaron patentemente na xestión da norma lingüística e moi especialmente do seu status simbólico. Con todo, a pesar destes desafíos, o

${ }^{1}$ Ignacio Francia: «Las Academias de la Lengua fijan las bases de la política lingüística panhispánica», El País, «Cultura», 15/09/2005, http://www.elpais.com/articulo/cultura/Academias/Lengua/fijan/bases/ politica/linguistica/panhispanica/elpepicul/20050915elpepicul_2/Tes 
movemento, nas súas distintas reencarnacións, sobrevive. Atreveríame a afirmar até que, na última década do século XX, adquiriu renovada enerxía ao se daren por fin, nun novo contexto xeopolítico, as condicións que fornecen o proxecto de combustíbel económico, argumentos políticos e soporte institucional.

En primeiro lugar, a partir dos 80 , un grupo de compañías de capital predominantemente español (representantes de múltiples sectores: financeiro, enerxético, editorial, telecomunicacións, turismo, construción, enerxías renovábeis) proxectábase internacionalmente e, coa complicidade de parte da clase política e empresarial local, escollían América Latina como campo de operacións privilexiado (Bonet e de Gregorio 1999, Casilda Béjar 2001). Xa a mediados dos 90, Jesús de Polanco, forxador do importante imperio editorial e mediático PRISA, asociaba, na mellor tradición panhispanista, a proximidade cultural ao dereito lexítimo do seu país para dirixir o punto de mira cara ás antigas colonias: «Iberoamérica es un objetivo político, económico y empresarial legítimo para los españoles [...]. Estamos mucho menos lejos de América Latina de lo que nadie puede pensar» (citado en El País, 24 de xullo de 1995). Unha década despois, produciríase a anunciada penetración, que xeraría, polo menos na opinión dalgúns líderes empresariais, un alto nivel de integración, de novo tal como o panhispanismo previra desde os seus inicios: «Lo que está pasando en Latinoamérica no se entendería sin la presencia de la empresa española, como tampoco se entendería el fortalecimiento de España en el mundo sin la expansión de la empresa española en Latinoamérica» (Francisco Luzón, conselleiro director xeral do Grupo Santander para América Latina, citado en El Pais, 10 de xullo de 2007). Nótese que, neste novo contexto en que as economías nacionais se abrían ao investimento estranxeiro, o desenvolvemento económico de España depende en boa medida das posibilidades de investimento na América Latina, e que este potencial se vincula inequivocamente á existencia dun pasado compartido e dunha herdanza lingüística común.

En segundo lugar, estas novas perspectivas de investimento para o capital español coincidían con profundas transformacións do sistema capitalista, como indicabamos hai un momento: globalizábase a economía mundial e relativizábase o poder dos Estados-nación, que se vían impelidos a responder perante as novas condicións xeopolíticas. Os procesos de integración rexional presentábanse en tal contexto como sine qua non para o desenvolvemento, e o nivel de pro- 
tagonismo de cada país nas diversas áreas percibíase como factor determinante do rol global que a cada un habería de corresponder. Se a mediados dos 80 España conseguía incorporarse ao vagón de atrás de Europa (ao que daquela se chamaba Comunidade Económica Europea), desde os finais desa década pasaba a se concentrar na súa política cara ao que cada vez con máis frecuencia se chama Iberoamérica, asumindo o liderado dun proceso de integración que, de se realizar con éxito, acabaría por conformar a Comunidade Iberoamericana de Nacións:

A principios de los años ochenta, que es cuando por parte española se empieza a plantear la oportunidad de celebrar una Cumbre Iberoamericana en torno a 1992, la posibilidad de que se celebrase una reunión de esta naturaleza y alcance y de que la Cumbre Iberoamericana obtuviese un cierto reconocimiento, aparecía en el horizonte de 1992 como algo remoto, casi imposible de lograr, en función del escenario internacional, de la diversidad y heterogeneidad de los países iberoamericanos y del todavía escaso nivel de las relaciones entre España e Iberoamérica. En este contexto, la realidad es que sólo la diplomacia española apostaba decididamente por este objetivo, sin que en esos momentos hubiera especial interés en los países iberoamericanos en apostar, más allá de la retórica, por el mismo (Del Arenal 1999: 206).

Os esforzos da diplomacia española acharían efectivamente as súas primeiras recompensas co cumio de Guadalajara, México, que tivo lugar os días 18 e 19 de xullo de 1991, e co cumio do Quinto Centenario, realizado en Madrid o 24 de xullo de 1992. Como foi sinalado polo diplomático chileno Raúl Sanhueza Carvajal, «el trabajo diplomático para consensuar esta iniciativa estuvo determinado por el ejercicio de un liderazgo español, el cual en esta etapa, asumió la forma de "liderazgo ejemplificador o pedagógico", caracterizado por la prudencia y una inspiración idealista» (2003: 38). Tendo en conta a complicada historia das relacións entre España e as súas antigas colonias, as múltiples disputas arredor do status relativo dos países americanos e a vella metrópole así como os receos ante as súas intencións e xestos paternalistas, non sorprende que a diplomacia deste país operase con especial prudencia. Nada máis lonxe dos seus obxectivos que a posíbel identificación de impulsos neocoloniais na proxección iberoamericana de España; de aí que se insistise en que «hay que dejar muy claro que no se trata 
de construir el equivalente de la francofonía, o la Commonwealth en las que las antiguas metrópolis juegan un papel hegemónico. En el caso español, la relación no es paterno-filial sino fraternal» (Papell 1991: 166). A proxección desta imaxe de irmandade, a ansia por elidir a preeminencia de España, que tanto dano fixera ao panhispanismo ao longo da historia (como vimos antes exemplificado no terreo da xestión do idioma), converteríase por tanto nun obxectivo prioritario para a diplomacia española.

Por iso, en terceiro lugar, ao tempo que, como acabamos de ver, se ían producindo, nos ámbitos económico e político, desenvolvementos en que se perfilaba a América hispanofalante como obxectivo preferente da política exterior española e que parecían esixir a activación do vello proxecto panhispanista, os sucesivos gobernos deste país (socialistas e populares) ían mobilizando axencias culturais que ofrecían soporte institucional e puñan en marcha accións ao servizo da defensa dos seus intereses xeopolíticos. Entre estas axencias, como indicabamos antes, destácase no ámbito da política lingüística a Real Academia Española.

Non se fixo aínda, que eu saiba, un estudo sistemático da relación entre a RAE e os medios de comunicación, pero é indubidábel, a partir dos traballos realizados sobre os discursos e produtos do dispositivo institucional de soporte ao idioma, que estamos perante unha fronte imprescindíbel. Os medios son un espazo, neste caso discursivo, onde a corporación procura implementar a súa política panhispánica; onde trata de normalizar e naturalizar unha visión do español que opera desde e sobre o campo xeopolítico; onde se produce e se reproduce o sistema lingüístico-ideolóxico da hispanofonía. Lembremos se non a estratéxica utilización dos premios de alto perfil, valiosos, desde a nosa perspectiva no só por seren recompensas aos fieis "paladíns do español» senón, sobre todo, pola utilidade da cobertura mediática que garante a presenza nos espectaculares actos de entrega de figuras tales como o rei Juan Carlos I. Estou a pensar, por exemplo, na concesión recente do Premio Don Quijote (da Fundación Santillana e da Xunta de Castela-A Mancha) á presidenta das Filipinas, Gloria Macapagal-Arroyo, e ao ínclito escritor peruano Mario Vargas Llosa. Na foto que publica El País o 16 de abril deste mesmo ano, acompañando un artigo titulado «Dos paladines del español global», aparecen, xunto cos galardoados, o presidente de Castela-A Mancha, os reis D. Juan Carlos e D. a Sofía e, na marxe dereita, como 
non, Ignacio Polanco, presidente do grupo PRISA. Estou a pensar tamén nos congresos internacionais da lingua española que, ademais de seren difundidos a través dunha impresionante plataforma dixital en liña, congregan xornalistas que representan os diferentes medios e, a través deles, fan chegar a súa mensaxe alén, moi alén, dos límites espazo-temporais do propio evento. Vale a pena recordar Medellín, Colombia, e o relato que o diario bonaerense Clarín facía dunha reunión previa ao IV Congreso Internacional da Lingua Española que tivo lugar en Cartagena de Indias. O 24 de marzo de 2007, a fermosa e engaiolante cidade colombiana servía de marco para a celebración dun acontecemento que, a pesar da súa aparencia, en principio banal, era motivo nesta ocasión dunha sorprendente cobertura mediática: a Asociación de Academias da Lingua Española reuníase no trixésimo congreso desde a súa concepción en 1951. A xunta comezou o 21 e atinxiu o seu cumio climático tres días despois, no Teatro Metropolitano, durante o que se podería cualificar como un dos acontecementos máis publicitados da historia do idioma: a aprobación oficial da Nueva gramática de la lengua española. O presidente da Colombia, Álvaro Uribe, e o titular da Coroa española, o rei Juan Carlos I, presidían a cerimonia. Despois da lectura protocolaria de discursos de benvida e agradecemento, o Rei encarou os académicos -1 de España, 1 das Filipinas e 20 das Américas - e dirixiulles por quenda a seguinte pregunta: «¿Aprobáis la Nueva Gramática?». Cada un —ante o distinguido panel de empresarios, políticos, editores e xornalistas que acompañaba como testemuñas - respondeu, ao chegar o seu momento, cun simple mais inequívoco «sí».

Vaiamos máis atrás inclusive, agora a través dos premios. Situémonos en Oviedo, España, no ano 2000. Ou, mellor aínda, situémonos ante a reprodución gráfica do evento que foi feita nin máis nin menos que na revista ;Hola! No número do 9 de novembro, a famosa revista do corazón publicaba a dobre páxina unha foto tomada uns días antes, durante a cerimonia de entrega dos premios Príncipe de Asturias. O centro do retrato é dominado pola maxestática figura do príncipe Felipe. Arredor del posan os receptores do prestixioso premio. Á súa esquerda, destácase o rostro radiante de Víctor García de la Concha, veterano catedrático da Universidade de Salamanca e director da Real Academia Española desde 1998. Detrás deles, sobre unha tarima de varios niveis, os directores das academias americanas e filipina da lingua española locen amplos sorri- 
sos e un inconfundíbel aire de plenitude. Non é para menos: a Coroa española acaba de distinguir a nobreza lingüística, a Asociación de Academias da Lingua Española, co Premio Príncipe de Asturias da Concordia; polo seu contributo —anúnciasenos - á harmonía e á coexistencia pacífica entre os pobos hispánicos.

Abonde esta evidencia anecdótica para subliñar a importancia estratéxica dos medios de comunicación na proxección da política lingüística panhispánica. E baste tamén esta evidencia, por agora, para subliñarmos a centralidade dos medios na análise (necesariamente multimodal) da produción e reprodución de ideoloxías lingüísticas. A simple observación crítica deste díptico (previa a un xesto analítico máis sistemático) preséntanos os protagonistas das políticas lingüísticas panhispánicas, remítenos ao espazo transatlántico sobre o cal esas políticas ambicionan proxectarse —outorgándolle así materialidade polo menos discursiva a un territorio que carece de entidade política- e revélanos a escenificación dun modelo organizativo paradoxal onde o consenso — esa máxima democrática que se afirma no evocador premio da concordia - se sustenta en estruturas de lexitimidade xa non só xerárquicas (condición talvez necesaria de toda colectividade) senón evocadoras dunha orde inequivocamente colonial.

\section{CONCLUSIÓN}

Desde a proposta que aquí realizo, os medios de comunicación son concibidos en efecto como espazos discursivos onde se producen e reproducen ideoloxías lingüísticas, é dicir, onde as representacións da linguaxe e as actividades de organización do universo comunicativo se revelan integradas nun proceso máis amplo de organización de fronteiras sociais, de distribución de recursos e de lexitimación dese repartimento perante os ollos dos actores sociais envolvidos. Interésannos, desde esta perspectiva, os medios de comunicación en canto textos e prácticas discursivas e metadiscursivas que determinan aquilo que constitúe ou non a lingua ou a linguaxe lexítima, que valoran e sancionan determinadas exhibicións de competencia comunicativa fronte outras ou que confiren lexitimidade a falantes concretos en contextos concretos. Nos medios de comunicación revélasenos que a xestión da linguaxe significa a xestión da orde social. 
Os medios de comunicación desempeñan un papel central na construción de ordes políticas tales como a nación moderna, o Estado e o Imperio, así como de subxectividades sobre as cales se desenvolven diversas maneiras de relación con aquelas, tales como a cidadanía. A construción dunha relación entre individuo ou colectividades e linguaxe (coa linguaxe como praxe e como valor simbólico) foi parte importante da vida das nacións modernas e nas polémicas arredor dela interveñen de maneira destacada os medios de comunicación. É por iso que nos parece incompleta una socioloxía da linguaxe ou unha disciplina glotopolítica que non se impliquen na análise dos medios, tanto das prácticas discursivas que adoptan como da maneira en que tematizan a linguaxe. Noutras palabras, e recorrendo á terminoloxía clásica da teoría da comunicación, unha análise da linguaxe como código do cal se valen os medios e como contido da mensaxe. 
